\title{
O DESAFIO DA GESTÃO DE PESSOAS: A GES- TÃO DE DIVERSIDADE
}

\section{THE CHALLENGE OF PEOPLE MANAGEMENT: DIVERSITY MANAGEMENT}

Carla Cristina Gularte Liberato ${ }^{1}$

Resumo: A diversidade amplia os horizontes, apresenta novas possibilidades e incrementa $\mathrm{o}$ repertório. As corporações que estão à frente com suas iniciativas de capacitação e inclusão da diversidade notaram aumento de produtividade gerado pela colaboração e sinergia da equipe; além de flexibilidade decorrente do convívio com diferentes pessoas. Com intuito de conhecer o tema em ascensão na sociedade atualmente, realizamos revisão bibliográfica acerca do tema
"Gestão de diversidade" e suas interfaces, definição, desafios e o papel da tecnologia na gestão de pessoas. Sabemos da grandeza do tema e da dificuldade de sua implementação. Vivemos em um país diverso desde sua concepção, grandioso por natureza, receptivo a migrantes e imigrantes, mas ainda com imensas dificuldades no manejo das diferenças sociais.

Palavras chave: gestão de diversidade, gestão de pessoas, tecno-

1 Médica, Especialista em Cirurgia Vascular. Docente do Curso de Medicina da Faculdade de Ciências Biomédicas de Cacoal-RO- FACIMED. Coordenadora do Internato Médico

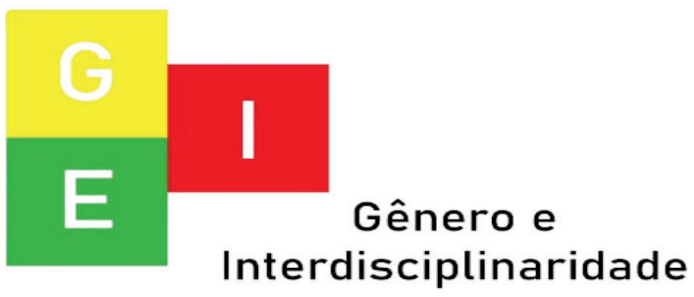


Vol. 02 - n 03 - ano 2021

Editora Acadêmica Periodicojs

logia na gestão de pessoas, tecnologia na gestão de diversidade e diversidade nas organizações.

Abstract: Diversity expands horizons, presents new possibilities and increases the repertoire. The corporations that are ahead with their training and inclusion of diversity initiatives have noticed increased productivity generated by the team's collaboration and synergy; in addition to flexibility resulting from living with different people. In order to get to know the topic on the rise in society today, we carried out a bibliographic review on the theme "Management of diversity" and its interfaces, definition, challenges and the role of technology in people management. We know the greatness of the theme and the difficulty of its implementation. We live in a country that was diverse since its conception, grand by nature, receptive to migrants and immigrants, but still with immense difficulties in the management of social differences.

Keywords: diversity management, people management, technology in people management, technology in managing diversity and diversity in organizations.

\section{Introdução}

Em todos os tempos da história existiram pessoas diferentes, grupos diferentes. Nossa sociedade é formada por pessoas diversas e as empresas não devem ignorar este fato. Afinal, são estas pessoas diferentes que também trabalham, lideram processos e equipes, são profissionais disponíveis no mercado e com habilidades que podem contribuir com o crescimento de

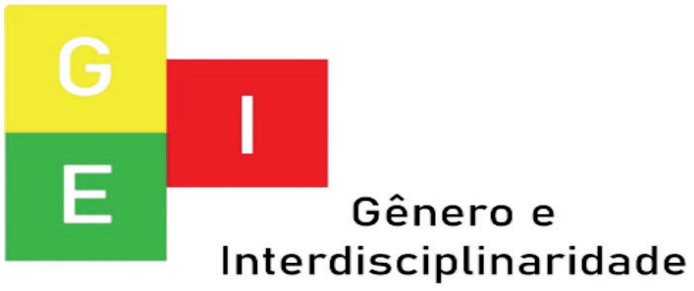


ISSN: 2675-7451

Vol. 02 - n 03 - ano 2021

Editora Acadêmica Periodicojs

organizações empresariais dos mais variados segmentos (Equipe IBC, 2020).

A sociedade se vai tornando mais heterogênea. As empresas têm papel fundamental no auxílio para a construção de um mundo mais igualitário, e engana-se quem pensa que essa função cabe apenas ao departamento de Recursos Humanos, toda a organização deve trabalhar em prol da diminuição da desigualdade de gênero, do preconceito quanto a orientação sexual e racismo, visto que todo e qualquer profissional, desde que qualificado para a vaga em questão, merece a chance de ser contratado (Equipe IBC).

A gestão bem sucedida de uma força de trabalho diversa constitui-se um dos desafios importantes para os líderes organizacionais. Esse desafio não reside na heterogeneidade da força de trabalho em si, mas na habilidade dos gestores em compreender a dinâmica da diversidade (Mor Barak (2005), citado por Pereira e Hanashiro, p. 672, 2010).

\section{Metodologia}

Estudo realizado entre os meses de junho e julho de 2020, através de revisão bibliográfica atual, sobre o assunto Gestão de Diversidade, abordando seu conceito, sua importância, evolução, principalmente no Brasil, os desafios e a inserção das tecnologias na Gestão de Pessoas a luz das modernas configurações da sociedade em franca modificação.

A revisão bibliográfica utilizou as palavras chaves "gestão de diversidade", "gestão de pessoas", "tecnologia na gestão de pessoas", "tecnologia na gestão de diversidade" e "diver-

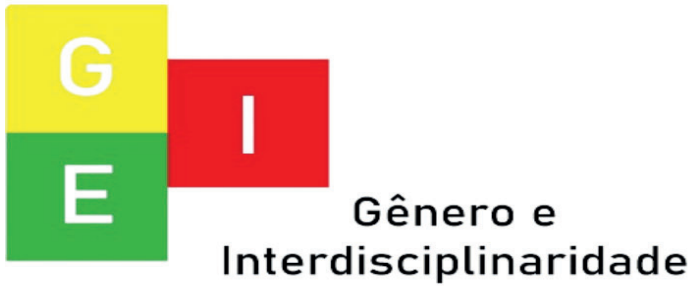


Vol. 02 - n 03 - ano 2021

Editora Acadêmica Periodicojs

sidade nas organizações". Realizamos pesquisa em fontes de pesquisa através do Google, com atenção a periódicos, livros e sites de divulgação na internet.

APLICAÇÃO NO CASO EM ESTUDO:

\section{DIVERSIDADE}

O conceito de diversidade é amplo e complexo, pois se refere a vários tipos de diferenças, não se restringindo apenas às minorias (mulheres, negros, homossexuais, dentre outros) como é comumente associado (Costa (2014), citado por Maia, 2018, p.3).

Sua compreensão requer uma base teórica proveniente de várias áreas do conhecimento e é de natureza multidimensional (todos nós temos várias identidades cultural e social, ou seja, somos diversos em diferentes dimensões, mais visíveis ou menos visíveis). Além disso, caracteriza-se como fenômeno que ocorre no nível individual e didático, no que diz respeito à relação de supervisor e subordinado, grupal, no âmbito dos grupos de trabalho e organizacional (Pereira e Hanashiro, 2010).

A diversidade é a busca de sintonia entre organizações e sociedade, à medida que constrói abertura para uma economia e sociedade mais globalizadas; responde aos questionamentos morais e éticos em torno da igualdade de direitos e oportunidades; reduz reivindicações, problemas jurídicos e exposição negativa de imagem das organizações diante do risco de acusações de discriminação e preconceito; contribui para a construção de ambientes organizacionais mais ricos, estimulantes e mais representati-

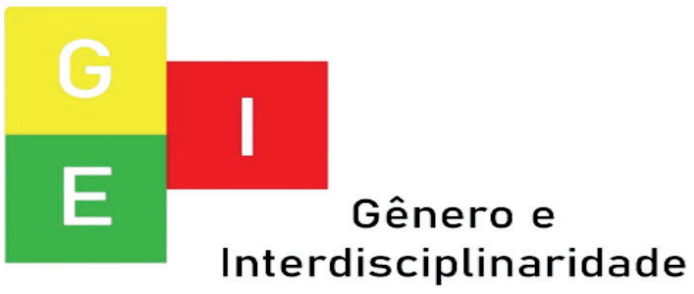


ISSN: 2675-7451

Vol. 02 - n 03 - ano 2021

Editora Acadêmica Periodicojs

vos da face humana; e capitaliza e mobiliza forças criativas em seus benefícios em virtude da maior riqueza de análise de equipes multiculturais (Chanlat,Dameron,Freitas,Dupuis e Özbilgin,2013).

Lidar com as diferenças implica valorizar o hibridismo cultural, em que similares e dissimilares possam conviver lado a lado. $\mathrm{E}$ isso significa para as organizações não apenas introduzir práticas de diversidade que enalteçam o valor das diferenças e meios de lidar com elas, mas conseguir que os seus empregados sejam envolvidos com elas (Pereira e Hanashiro, 2010).

A diversidade está presente em todos os âmbitos, sejam eles organizacionais ou não, e, mesmo dentro de uma organização onde o principal objetivo é o lucro, as ações voltadas à gestão de diversidade deve reconhecer que cada elemento é único e insubstituível, sendo as pessoas o foco mais importante dentro da organização. É também o caminho para que as empresas se tornem mais inovadoras, capazes de produzir bens úteis e tornar os seus trabalhadores incluídos, realizados e motivados. Uma empresa está sempre em busca de resultados econômicos, porém não podem ser implantadas políticas de diversidade na organização apenas como estratégias dedicadas exclusivamente a estas metas financeiras. Elas devem ser um compromisso moral que a empresa assume com a sociedade (Santos, Santana e Arruda,2017). Independentemente das perspectivas adotadas - por exemplo, de gênero, etnia, idade, religião ou orientação sexual - evidências dão conta de que o perfil da força de trabalho vem se diversificando cada vez mais nas

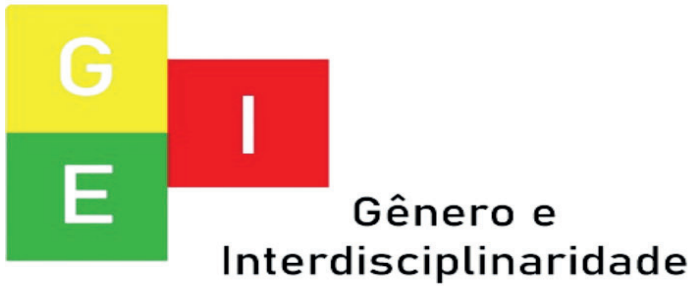


ISSN: 2675-7451

Vol. 02 - n 03 - ano 2021

Editora Acadêmica Periodicojs

últimas décadas. Esta diversida-

de de colaboradores seria benéfi-

ca em dois pontos de vista, pri-

meiro promoveria o sentimento

de justiça, onde os colaboradores

possuiriam condições iguais por

merecimento e não favorecimen-

to; segundo conduziria à criação

de vantagem competitiva, o que,

em tese, elevaria o desempenho

da organização no mercado, ten-

do em vista a influência positiva

de um ambiente interno multicul-

tural, com membros de distintas

experiências e habilidades (Alves

e Galeão-Silva, 2004).

\section{DIVERSIDADE NO BRASIL}

A diversidade no cenário brasileiro pode ser facilmente percebida sob inúmeras perspectivas: nas etnias, nas características regionais, no pluralismo religioso, em traços demográficos e econômicos, por exemplo (Maia,
2018).

Em um país como o Bra-

sil, com uma sociedade heterogênea e com muitas desigualdades sociais, o tema da diversidade cultural assume relevância. Trabalhar e denunciar o imaginário popular de uma sociedade livre de preconceitos, cujo acesso às posições no sistema educacional e no mercado de trabalho é aberto a todos, é importante para fazer avançar essas questões num país que se quer democrático (Fleury, 2000).

Vivemos em um país diverso e as empresas necessitam compreender que essa característica tende a beneficiar os seus resultados, em contrapartida é necessário possibilitar o sucesso profissional e condições para que as pessoas tenham um desenvolvimento constante (Neves, 2000). Percebe-se que ainda estamos dando os primeiros pas-

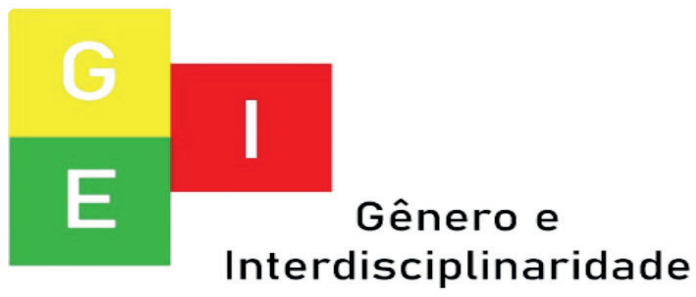


ISSN: 2675-7451

Vol. 02 - n 03 - ano 2021

Editora Acadêmica Periodicojs

sos nesses estudos, ainda que tenham sido desenvolvidas, nas duas últimas décadas, várias leis e políticas públicas voltadas para reduzir desigualdades flagrantes e vergonhosas, que se manifestam nos mundos social e do trabalho. Ao longo dos anos, o Brasil construiu uma imagem de democracia racial, que esconde ou nega a vulnerabilidade de grupos minoritários e a perversidade conservadora de uma porcentagem da sociedade brasileira, que se julga representante exclusiva do País. Assim, ainda que tenha presenciado claras melhorias em vários sentidos, o Brasil continua cego, surdo e mudo, além de injusto e preconceituoso, em relação a parte do seu povo (Chanlat et al ,2013).

\section{GESTÃO DE DIVERSIDADE}

Em um ambiente cada vez mais competitivo e mutante, as organizações necessitam se adaptar a novas realidades e exigências de mercado. A gestão da diversidade se torna um aspecto vital para a sobrevivência de muitas empresas, tendo em vista a expertise que isso proporciona para o contexto organizacional e consequentemente a evolução das atividades empresariais ( $\mathrm{Ne}$ ves, 2000).

Fleury (2000) destaca que o objetivo principal da gestão da diversidade nas organizações é administrar as relações de trabalho e as práticas organizacionais para compor a sua força de trabalho interna, com vista a atração e retenção dos talentos que se encontram nos chamados grupos de minoria.

Para muitas empresas, a diversidade auxilia no alcance de metas e objetivos complexos que dificilmente seriam atingi-

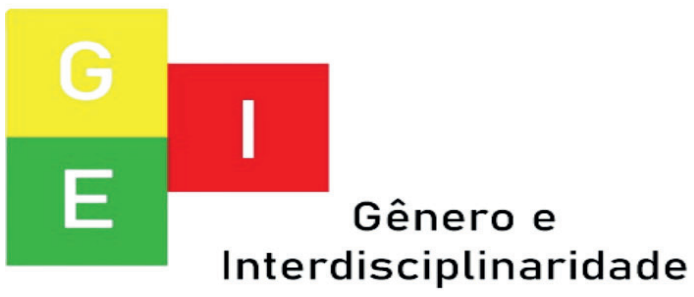


ISSN: 2675-7451

Vol. 02 - n 03 - ano 2021

Editora Acadêmica Periodicojs

dos se estas fossem cultural e etnicamente homogêneas. Nessas organizações, a área de Gestão de Pessoas passa a ter um papel central no sentido de desenvolver e sustentar a liderança necessária para a criação de um ambiente favorável à inclusão e ao respeito às diferenças individuais, no qual as pessoas têm possibilidade de crescimento, aprendizado e ainda contribuem para o êxito organizacional (Maia, 2018).

Pereira e Hanashiro, 2010, durante realização de seus estudos discutem as práticas de diversidade em ambiente corporativo, afirmando que estas práticas podem provocar diferentes reações nos diferentes indivíduos envolvidos direta ou indiretamente e que essa falta de unanimidade pode afetar os resultados dessas práticas. $\mathrm{O}$ conhecimento das reações destes indivíduos, assim como as dos demais, é de fundamental importância para a implantação, desenvolvimento de programas ou modelos mais efetivos de gestão da diversidade.

O cenário atual é marcado pela busca por direitos e oportunidades iguais para todos e, ao mesmo tempo, é caracterizado por indivíduos cada vez mais diversos. Neste momento, as organizações são chamadas a lidar com situações que ainda não são rotineiras, como convivência no ambiente organizacional entre pessoas muito jovens e outras mais velhas, maior quantidade de mulheres no cenário empresarial, colaboradores que requerem benefícios iguais para seus companheiros do mesmo sexo, entre outros. Assim, as demandas da atualidade requerem novas respostas e diferentes políticas das organizações especialmente no que tange ao relacionamento tanto com seu público interno quan-

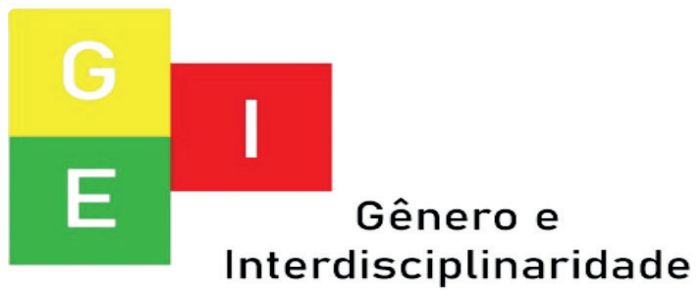


ISSN: 2675-7451

Vol. 02 - n 03 - ano 2021

Editora Acadêmica Periodicojs

to externo, e isso tem se refletido na busca pela adoção de práticas de gestão da diversidade (Maia, 2018)

De que forma a gestão da diversidade vem sendo incorporada às organizações brasileiras? Em extensa pesquisa e revisão bibliográfica acerca do tema, Maia (2018) entende que apesar de ainda existir uma grande lacuna no que se refere a estudos e informações quanto às políticas de gestão da diversidade, a revisão sistemática da literatura evidenciou que muitas práticas já vêm sendo adotadas nas organizações e que essas práticas, em alguns casos, extrapolam a visão simplista da compreensão da gestão da diversidade apenas como um cumprimento legal de inclusão de minorias e da busca do desenvolvimento de uma cultura organizacional verdadeiramente multicultural ao compreender e aceitar que o diferente pode apresentar-se de inúmeras formas. As práticas de gestão da diversidade impactam no desempenho organizacional e podem acarretar resultados tanto positivos quanto negativos. Por isso, é necessário que essas práticas sejam adequadamente gerenciadas visando a extrair o melhor da diversidade.

Segundo Fleury (2000) a gestão de diversidade é feita por políticas de recrutamento que incorporem os critérios relacionados à diversidade cultural do mercado de trabalho. Estas ações podem ser feitas através de recrutamento de pessoal, diversificando a força de trabalho para balancear seu corpo de empregados. Realização de treinamentos para conscientização das diferenças culturais além da criação de projetos de comunicação interna com a finalidade de divulgar os objetivos do programa de diversi-

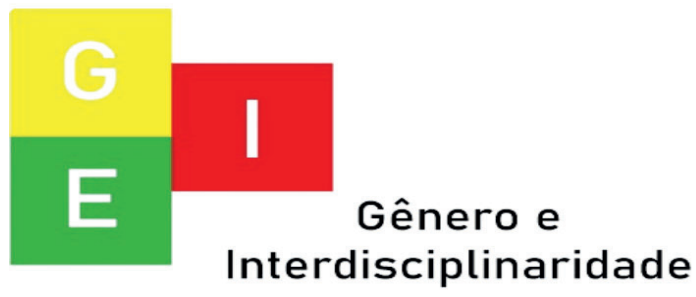


ISSN: 2675-7451

Vol. 02 - n 03 - ano 2021

Editora Acadêmica Periodicojs

dade a todos os empregados.

Em estudo realizado por Silva, Rodrigues, Ferreira e Queiroz (2020), buscou responder a pergunta de pesquisa "como a unidade brasileira de uma empresa multinacional desenvolveu e implementou um programa de diversidade e inclusão? Foi possível conhecer a estratégia da empresa que contou inicialmente com a formação de um Comitê de Diversidade. Tais comitês possuíam colaboradores voluntários e um líder; através de workshops, debates, rodas de conversa criaram um ambiente propício e de integração entre os funcionários com o intuito de engajar a liderança no tema, além de promover a conscientização e educação a respeito da diversidade aos colaboradores.

Para Brito (2014) uma forma de gestão de diversidade é a criação e estímulo de ambien- te pró-ativo na empresa, desta forma é possível a convivência com as diferentes culturas e as diferentes identidades sexuais, gerando aprendizado e através deste aprendizado, são criadas condições para que todas as identidades recebam um tratamento igualitário e de respeito. Inicialmente as ações ocorrem em momentos de laser, em almoços e jantares, permitindo que os colaboradores se conheçam. Seguindo com a Estratégia de Aprendizagem Formativa que enseja o aprendizado de como lidar com as diferenças através da informação e conhecimento. Os gestores proporcionam momentos de discussão sobre os temas, reflexão crítica de seus colaboradores e o desenvolvimento de um Código de conduta interno, com direitos e deveres de todos os colaboradores, incluindo punições em casos de desrespeitos ás regras

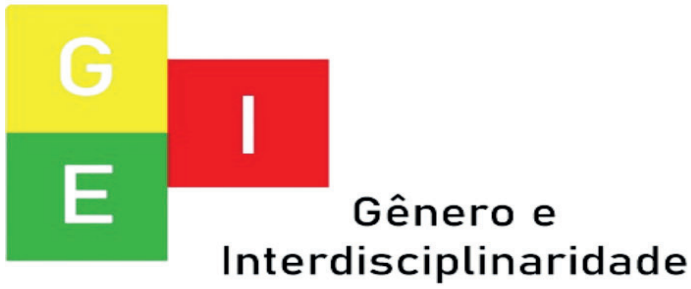


ISSN: $2675-7451$

Vol. 02 - n 03 - ano 2021

Editora Acadêmica Periodicojs

criadas e debatidas pelos pares. resultados significativos decor-

Para a autora o respeito e valorização da diversidade sexual nas organizações contribuem para o reconhecimento das pessoas na sua pluralidade humana, melhorando as relações interpessoais, afetando positivamente a saúde e a qualidade de vida. A partir do momento em que as pessoas se sentirem respeitadas, incluídas e se sentirem parte da organização onde trabalham, tudo muda em favor delas próprias e consequentemente acaba refletindo positivamente para as organizações.

Um fator relevante no momento de decisão para a implementação ou não de uma política de diversidade está pautado nas mudanças que vão além de procedimentos administrativos, pois é preciso uma mudança cultural (Alves; Galeão-Silva, 2004).

Pesquisas comprovam rentes de políticas de valorização da diversidade nas organizações, tais como melhor entendimento das necessidades dos clientes; fortalecimento financeiro, inclusive com a participação de novos investidores; satisfação dos profissionais no trabalho, com redução da rotatividade e aumento da produtividade; redução da vulnerabilidade legal, e fortalecimento da imagem corporativa. Complementarmente, é necessário definir a estratégia de desenvolvimento, implementação e avaliação da política; construir o compromisso da alta administração com a diversidade; estabelecer mecanismos de integração da iniciativa com a gestão; promover a erradicação de preconceitos e discriminações, e incentivar a aproximação dos grupos que compõem a diversidade da empresa (Klinke).

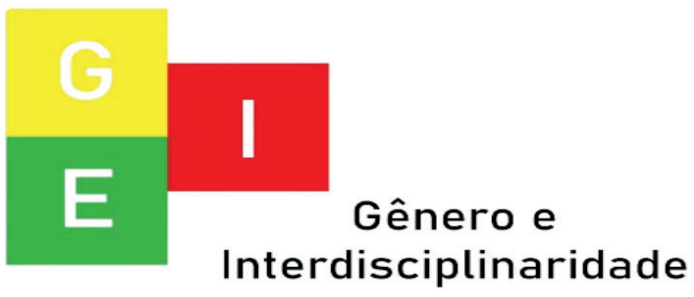


ISSN: $2675-7451$

Vol. 02 - n 03 - ano 2021

Editora Acadêmica Periodicojs

Há algumas vantagens e Inclusão (D\&I) no mercado para as empresas que implande trabalho e a crescente importam a gestão da diversidade, tais tância que esses softwares têm como: redução de problemas ganhado, a Mercer afirma que o jurídicos, exposição negativa mercado de tecnologia de D\&I e reivindicação diante do risco está crescendo em ritmo acelerade preconceito e discriminação; do, com clientes principalmente construção de ambientes organizacionais mais ricos, representativos e estimulantes; mobilização e capitalização de forças criativas por conta da maior riqueza de análise de colaboradores multiculturais; abertura para uma sociedade e uma economia mais globalizadas; resposta aos questionamentos éticos e morais em torno da igualdade de oportunidades e direitos; a empresa apresenta um grande potencial de inovação, de performance e criatividade por conta da diversidade de ideais, pensamentos e culturas (Ambra,2018).

Analisando os impactos das tecnologias de Diversidade nas áreas de finanças e tecnologia. A maior parte das soluções existentes até o momento (43\%) concentra-se na aquisição de talentos, enquanto apenas $12 \%$ são desenvolvidas para engajamento e retenção de funcionários (Garr e Jackson,2019).

Segundo a Endeavor (2020) por maior que tenha sido o avanço em Diversidade e Inclusão (D\&I) nos últimos anos, ainda há um longo percurso para ser percorrido, principalmente quando olhamos para times de tecnologia. As vantagens da D\&I são possibilidade da criação de ideias melhores propiciadas por vivências distintas; melhor conexão

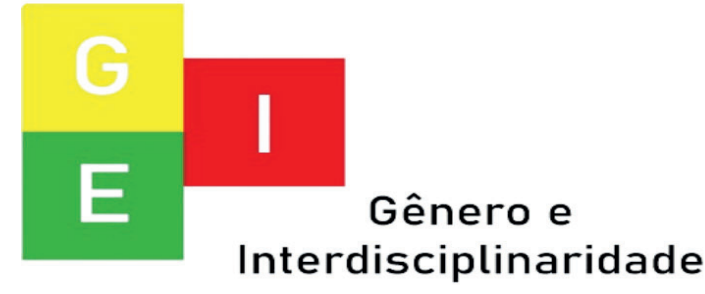


ISSN: 2675-7451

Vol. 02 - n 03 - ano 2021

Editora Acadêmica Periodicojs

com o s clientes, pois o público também é heterogêneo; maior alcance dos produtos; aumento da lucratividade e crescimento interno. Para ser efetivo, D\&I não deve ser responsabilidade de um profissional ou do $\mathrm{RH}$, mas de toda a empresa. As iniciativas estão também na maneira com que times se integram, na forma de conduzir programas, na criação de eventos inclusivos e na mensagem que a companhia passa internamente e externamente. Promover a diversidade é bem visto hoje em dia, e criar uma cultura com boa reputação, sem dúvidas, é vantajoso para a empresa.

A diversidade no ambiente de trabalho pode trazer experiências únicas e uma variedade de soft skills altamente valorizadas atualmente, como colaboração, comunicação, inovação e pensamento criativo. Além disso, esse leque mais amplo de funcionários permite que os anseios dos clientes - que também são plurais - sejam mais bem compreendidos. Assim, a empresa pode atender melhor suas expectativas - um benefício real e tangível em termos comerciais. Hoje, soluções baseadas em inteligência artificial podem ajudar os empregadores desde a etapa de recrutamento além de proporcionar análises regulares sobre remuneração e benefícios, para combater disparidades salariais em toda a força de trabalho (Bravo,2020).

A implementação da tecnologia da informação vem sendo considerada uma maneira de viabilizar novos arranjos organizacionais da gestão de pessoas. A implementação crescente dos chamados sistemas de $\mathrm{RH}$ autoatendimento é um indicativo desta tendência. Estes sistemas possibilitam o amplo acesso do

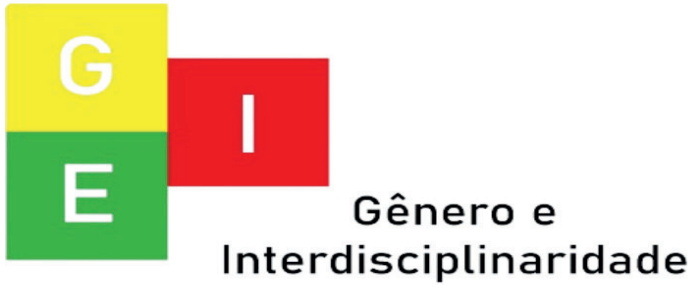


ISSN: 2675-7451

Vol. 02 - n 03 - ano 2021

Editora Acadêmica Periodicojs

funcionário a informações e funções personalizadas e relevantes para a administração de seu relacionamento com a organização (Mascarenhas e Vasconcelos, 2005). Segundo os autores o uso do autoatendimento proporciona aos funcionários a interação entre ele e a empresa, funcionários entre si, funcionários ás tarefas e funcionários a sua vida fora do ambiente laboral.

A informatização dos processos de gestão de pessoas e os novos padrões de acesso à informação permitiram a transformação do relacionamento entre gestores de linha e subordinados, na medida em que os novos processos de RH demandam a aproximação entre eles. A gestão de pessoas passou a ser um processo em que a interação direta de chefes e subordinados ganha contornos mais estratégicos e maior importância, o que vai ao encontro de princípios de gestão, segundo os quais essa é uma atividade que faz parte da dinâmica entre líderes e equipes. Neste novo contexto, a área de RH deixou de ser o intermediário nas negociações dos gerentes e seus subordinados no que diz respeito aos múltiplos interesses constantemente em jogo (Mascarenhas e Vasconcelos, 2005).

A utilização de ferramentas tecnológicas nos processos que envolvem a gestão de pessoas é uma grande aliada para os gestores de RH e possibilita melhorar os resultados da equipe, além de otimizar ferramentas e atividades. Entre essas ferramentas, podemos citar sistemas de gestão, plataformas colaborativas, aplicativos, people analytics, e-learning e até redes sociais corporativas. A utilização de sistemas diferentes para diversos fins tende a consumir mais

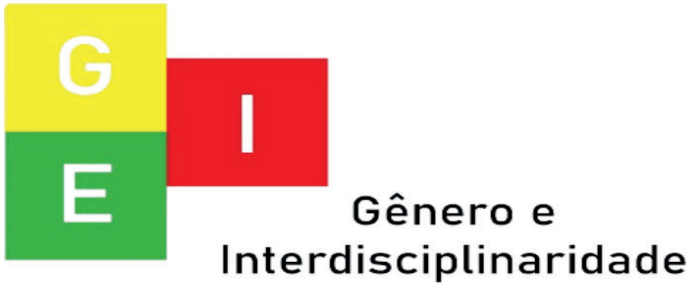


ISSN: 2675-7451

Vol. 02 - n 03 - ano 2021

Editora Acadêmica Periodicojs

tempo de trabalho, pois dificilmente eles são integrados, mas a tecnologia para $\mathrm{RH}$ já oferece soluções nesse sentido, como os softwares de gestão. Estas tecnologias propiciam otimização de tempo, agilidade e transparência dos processos, permitindo que o funcionário de $\mathrm{RH}$ realize tarefas mais complexas, melhora o recrutamento de funcionários, promove a diversidade no ambiente de trabalho, desenvolve pessoas, engaja os colaboradores, otimiza processos, além de permitir o desenvolvimento de visão estratégica, ou seja, a capacidade de enxergar a realidade da companhia e do mercado e, diante do contexto, se preparar para o futuro. Por esse motivo, o RH é visto como uma área fundamental para qualquer organização, e a tecnologia na gestão de pessoas é um diferencial competitivo (Braga, 2019).
Julio (2020) durante re-

dação a Revista Época Negócios cita Jaques Haber, da iiGual Inclusão \& Diversidade, afirmando que reunir a habilidade humana à alta tecnologia é o segredo de um negócio bem-sucedido. $\mathrm{Na}$ revolução digital, o ser humano deve ser o protagonista. "A tecnologia traz inúmeras possibilidades para aumentarmos o impacto social no mundo".

\section{Considerações Finais}

A diversidade vem sendo tratada de forma desigual e discriminatória. O Brasil, apesar de ser um país fortemente marcado pela diversidade desde sua origem, é ainda um país onde a diversidade só é lembrada em momentos pontuais. Não há ainda uma política efetiva de valorização e respeito a ela (Brito,2014).

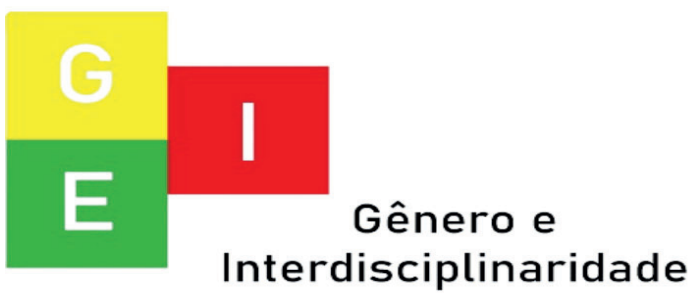


ISSN: 2675-7451

Vol. 02 - n 03 - ano 2021

Editora Acadêmica Periodicojs

Vivemos imersas/os em

um verdadeiro caldeirão cultu-

ral efervescente onde diversas culturas estão interagindo e as identidades estão em permanente movimento.

Não tem como escapar dos efeitos da diversidade presentes nos mais variados contextos sociais. Além do mais, é indiscutível o fato das sociedades estarem cada vez mais próximas. Se percebe isso a partir da comunicação, através do uso cada vez maior da internet, dos intercâmbios culturais, dos movimentos migratórios das pessoas pelo mundo, das parcerias comerciais nacionais e internacionais etc. Contudo, o fato das sociedades estarem mais próximas, não estão isentas de conflitos (Brito, 2014).

Acontecimentos recentes trouxeram a tona a discussão fervorosa em prol da diversidade.
Com a evolução da sociedade, mundialmente, as pessoas precisam refletir sobre o tema, ter um posicionamento favorável ás pessoas discriminadas. O mesmo deve ocorrer nas empresas, é sabido que a diversidade entre os colaboradores permite alavancar os lucros, mas, por outro lado, funcionários satisfeitos e respeitados são mais eficazes, expõe melhor as suas ideias, otimizam o tempo para realizar suas tarefas. A empresa ganha no contexto da sociedade por ser exemplo a seguir. A sociedade ganha pela inclusão de pessoas muitas vezes talentosas, mas marginalizadas pela sua condição social diversa. As pessoas são diversas, o mundo é diverso, porque nosso pensamento e forma de agir deve possuir um padrão? Padrões muitas vezes inatingíveis, distantes da maioria.

Com o recente avanço

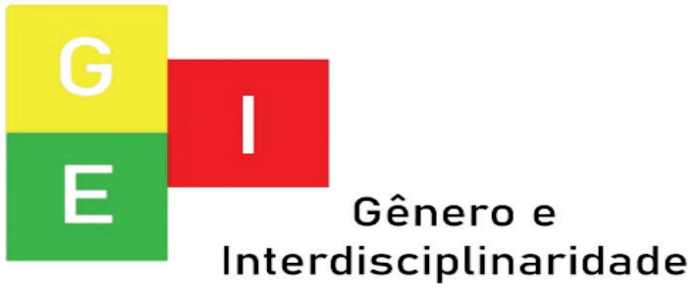


ISSN: 2675-7451

Vol. 02 - n 03 - ano 2021

Editora Acadêmica Periodicojs

tecnológico e a criação de softwares de gestão é possível realizar recrutamento eficaz de pessoal baseados nas características de desempenho da pessoa, eliminando o viés discriminatório. Promover o debate do assunto dentro da empresa é salutar, imprescindível. A criação de "Códigos de conduta" pelos pares é uma forma de deixar todos a vontade na condução do assunto. Ao gestor cabe administrar as diferenças de forma a satisfazer seus liderados, promovendo maior produção, em ambiente de trabalho salubre e dinâmico, com respeito ás pessoas inseridas na organização. Respeitar as diversidades é uma característica indispensável a um bom líder e gestor.

\section{Revisão Bibliográfica}

Alves, Mario Aquino, \& Galeão-Silva, Luis Guilherme. (2004).
A crítica da gestão da diversidade nas organizações. Revista de Administração de Empresas, 44(3), 20-29.

Ambra. Gestão da diversidade tem a ver com a gestão de talentos? June 18, 2018. https://blog. ambra.education/gestao-da-diversidade/acesso 13/07/2020

Braga,M. Confira 8 vantagens da tecnologia na gestão de pessoas. Site Reachr, 9 de setembro de 2019. https://www.reachr.com.br/ novo-blog/confira-8-vantagens-da-tecnologia-na-gestao-de-pessoas/acesso 15/07/2020

Bravo,L. Como a tecnologia pode fomentar a diversidade no mercado de trabalho. 10/02/2020. https://www.whow.com.br/negocios/como-tecnologia-pode-fomentar-diversidade-trabalho/ acesso 15/07/2020

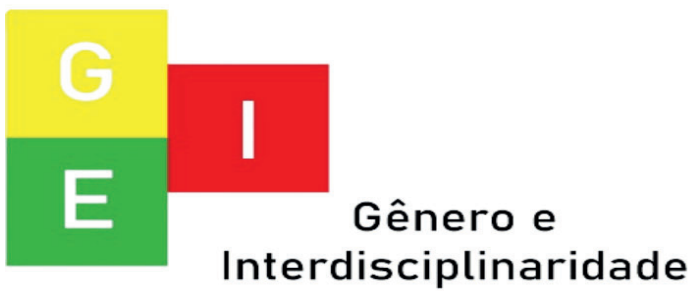


ISSN: 2675-7451

Vol. 02 - n 03 - ano 2021

Editora Acadêmica Periodicojs zado em: 26 de maio, 2020. ht-

Brito, Jaqueline Gil. Estratégias pró-ativas da diversidade sexual nas organizações / Jaqueline Gil Brito. - 2014. 99 f. Orientador: Prof. Dr. Eduardo Davel. Dissertação (mestrado) - Universidade Federal da Bahia, Escola de Administração, Salvador, 2014.

Chanlat,J.F.;Dameron,S; Freitas, M.E.;Dupuis,J.P.;Özbilgin,M. Desafios da Gestão da Diversidade nas Organizações. Artigo em foco: Management et Diversité: Approches Théoriques, Approches Comparées.2013.https://pesquisa-eaesp.fgv.br/publicacoes/ gvp/desafios-da-gestao-da-diversidade-nas-organizacoes acesso $13 / 07 / 2020$

Endeavor.Diversidade e Inclusão: crie times de tecnologia mais heterogêneos. Publicado em: 23 de novembro, 2018 | Atuali- tps://endeavor.org.br/tecnologia/ diversidade-e-inclusao-5-formas-de-criar-times-de-/tecnologia-mais-heterogeneos/ acesso $15 / 07 / 2020$

Equipe IBC. Gestão da diversidade nas empresas: realidade e desafios. Postado em 15 de outubro de 2019.https://www. ibccoaching.com.br/portal/gestao-da-diversidade-nas-empresas-realidade-e-desafios/ acesso 13/07/2020.

Fleury, M. T. L. Gerenciando a Diversidade Cultural: Experiência de Empresas Brasileiras. RAE-revista de administração de empresas, v. 40, n. 3, p. 18-25, 2000.

Garr, S.S.;Jackson,C. Diversity \& Inclusion Technology: The Rise of a Transformative Market.

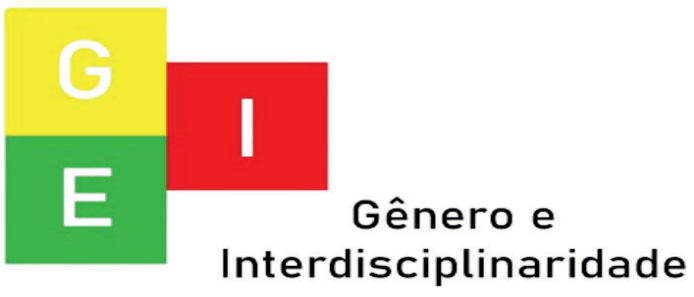


ISSN: 2675-7451

Vol. 02 - n 03 - ano 2021

Editora Acadêmica Periodicojs

Mercer February 2019. https:// Revista CONBRAD, v. 3, no 01

www.mercer.com/content/dam/ - 2018.

mercer/attachments/private/gl-

-2019-mercer_di_report_digital.

pdf acesso 15/07/2020.

Mascarenhas, A O; Vasconcelos,

F C e Vasconcelos, I F. G. Im-

pactos da tecnologia na gestão de

Julio,R.A. Como a tecnologia pessoas: um estudo de caso. Re-

e a inclusão mudarão o futuro vista de Administração Contem-

do mercado de trabalho. Épo-

porânea, 2005, 9(1), 125-147.

ca negócios. 19/03/2019.https://

epocanegocios.globo.com/Car-

reira/noticia/2019/03/como-tec-

nologia-e-inclusao-mudarao-o-

-futuro-do-mercado-de-trabalho.

html acesso 15/07/2020

Neves, A. Gestão da Diversidade nas Organizações como Prática Gerencial. Revista Gestão \& Sustentabilidade, 2020,2(1), 140154.

Klinke,M.A gestão da diversi- Pereira,J.B.C.; Hanashidade. Ecosocial.http://ecosocial. ro,D.M.M. Ser ou não Ser Favocom.br/desenvolvimento-huma- rável às Práticas de Diversidade? no/noticia/artigo-a-gestao-da-di- Eis a Questão. RAC, Curitiba, v. versidadeacesso 13/07/2020 14, n. 4, art. 6, pp. 670-683, Jul./ Ago. 2010. Disponível em http://

Maia,P.L.O. Gestão da diversiwww.anpad.org.br/rac. Acesso dade no contexto organizacional em $12 / 07 / 2020$ brasileiro: um enfoque sob a revisão sistemática da literatura.

Santos,J.V.M.; Santana,A.C.;Ar-

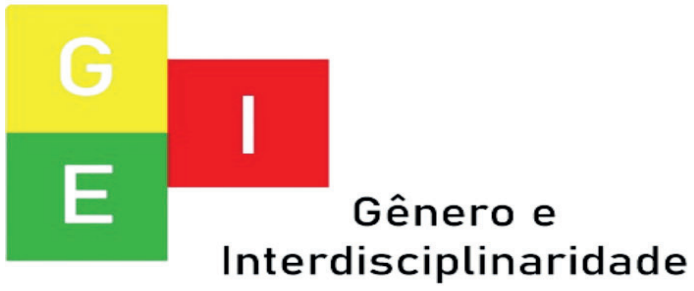


ISSN: 2675-7451

Vol. 02 - n 03 - ano 2021

Editora Acadêmica Periodicojs

ruda,G.D. A. DIVERSIDADE

NAS ORGANIZAÇÕES: IN-

CLUSÃO SOCIAL OU ES-

TRATÉGIA COMPETITIVA?

Psicologia.pt.2017 https://www.

psicologia.pt/artigos/textos/

A1170.pdf acesso 13/07/2020

Silva,J.T.;Rodrigues,I.; Ferreira,G.T.C.; Queiroz,M.J.Q. PILARES DA DIVERSIDADE E INCLUSÃO EM UMA MULTINACIONAL. Recape. Vol. $10 \mid$

$\mathrm{N}^{\circ}$ 1, ano 2020 Páginas 43-62

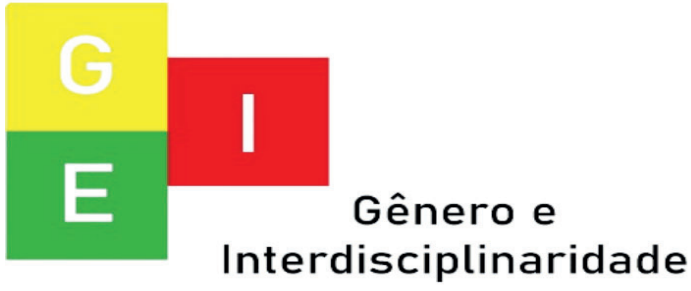

